\title{
24h Creep Test of PE1000 Material at Elevated Temperatures
}

\author{
Bogusz Paweł ${ }^{1, a^{*}}$, Grzeszczuk Wojciech ${ }^{2, b}$ \\ ${ }^{1}$ Faculty of Mechanical Engineering, Military University of Technology, \\ 00-908 Warsaw, Witolda Urbanowicza Street 2, Poland \\ apawel.bogusz@wat.edu.pl, bwojciech4741@gmail.com
}

Keywords: Polyethylene, Creep Tests, Mechanical Properties, Experimental Mechanics

Abstract. Plastics, also referred to as polymeric materials, are among basic groups of engineering materials. Creep in plastics, generally, results from the chains straightening, their relative to each other and orientation in the acting force direction. The main factors initiating the occurrence of the rheological phenomena are load and temperature. A wide range of the plastic materials applications includes elements exposed to long-term loads and working at elevated temperatures, which leads to conduct rheological tests. The UHMW (ultra-high molecular weight) type PE1000 polyethylene, in the form of a $4 \mathrm{~mm}$ thick plate was tested experimentally. A test program was established using three creep constitutive function variables: temperature, load and time. The maximum duration of the tests was set to 24 hours. Three temperature values, $22^{\circ} \mathrm{C}, 42^{\circ} \mathrm{C}$ and $90^{\circ} \mathrm{C}$, were chosen based on the characteristics of the material. Loading values at creep were selected based on the static tensile tests, which were carried out for each given temperature. The reference point was the material strength of the polyethylene at a given temperature. The samples were stressed with seven multipliers of the ultimate strength, from 0.9 to 0.4 , at a given temperature. Creep curves, creep parameters as well as mechanical strength properties of the tested PE1000 material for various stress levels and temperatures were obtained. A temperature increase degrades the strength and creep parameters of the material.

\section{Introduction}

The material investigated in the paper is polyethylene UHMW (ultra-high molecular weight) - a polyolefin type plastic material i.e., polymer containing only carbon and hydrogen atoms [1]. It is characterised with a number of excellent performance properties such as significantly high resistance to friction wear and perfect sliding properties. These properties are utilised to produce various machine and equipment components, such as bars, sliding guides used on factory production lines, gears, chain wheels, etc [2], [3]. PE-UHMW is also used as an additional cover material to protect surfaces from abrasion, therefore, it is used in cargo spaces in cars or railway wagons. PE-UHMW with its high impact resistance is used in production of various elements operated at low temperatures and exposed to impact loads, for example, fenders, bands and others. It has a number of applications in fuel-energy, electromechanical, textile and armament industries. It is worth mentioning that this material is inert in contact with a human tissue, which allows utilising it in the medical industry [4] and [5].

Plastic materials combine the characteristics of an elastic body and viscous liquid, which is called viscoelasticity. While examining the rheological phenomena in viscoelastic materials, the basic role is attributed to a time factor that determines the tested material behaviour under certain stress conditions. Rheological phenomena include creep and relaxation.

The structure of plastics consists of individual chemical compounds - monomers that are combined into long chains to form a polymer. Creep results from the chains straightening, their relative to each other movement and orientation in the acting force direction. [6]. The main

(c) (1) Content from this work may be used under the terms of the Creative Commons Attribution 3.0 license. Any further distribution of this work must maintain attribution to the author(s) and the title of the work, journal citation and DOI. Published under license by Materials Research Forum LLC. 
factor initiating the occurrence of the rheological phenomena is (apart from the load) the temperature.

A wide range of the material applications, including elements exposed to long-term loads and working at elevated temperatures, lead to conduct rheological tests. Moreover, polymer materials tend to deform even at low temperatures and under the influence of seemingly small loads. This phenomenon is not desirable and has a profound effect on the usability of an element made of such a material. Therefore, a plastic creep phenomenon needs to be taken into account at the product design stage. The material is usually selected and engineered to operate at a specific temperature and at a specified permanent load, therefore, the creep phenomenon can occur in a limited and predictable manner. In this case, a creep curve is similar to a straight line parallel to the timeline [7], [8]. This simplified approach can be insufficient in more demanding applications.

Proper multiple-stepped creep tests are generally time consuming, expensive and should be carefully planned. A $24 \mathrm{~h}$ time frame of creep test, presented in the paper, can be a reasonable option for practical applications and sufficient for numerical modelling purposes. In a few papers, the authors conducted creep research in time limited to $24 \mathrm{~h}$.

In the $\mathrm{PhD}$ thesis [9], time-dependent constitutive relationships for various polymers polyethylene materials were carried out. The experimental results indicated strong nonlinear viscoelasticity in the material responses. Samples of seven polyethylene materials were tested. Six of them were high density polyethylene (HDPE) and one was medium density polyethylene (MDPE). 24-hour creep tests on seven materials were conducted for modelling purposes. Moreover, multiple-stepped creep tests were also performed. All the tests were conducted at room temperature.

It was observed that at high stress levels a creep strain grows rapidly from the beginning of the test and a large deformation occurs within the first two hours. An excessive deformation, far beyond the practically acceptable levels, was observed. A hardening plateau was observed closer to the end of the tests.

In paper [10], the authors developed a method for constitutive nonlinear viscoelastic modelling of polyethylene utilizing both the multi-Kelvin element theory and the power law functions to model a creep compliance. Creep tests were used to determine material parameters and models. Four different PE materials were tested in creep for $24 \mathrm{~h}$. Three of the materials were specified as HDPE and one as MDPE. Five stress levels were set.

\section{Experimental research}

The UHMW (ultra-high molecular weight) type polyethylene PE1000, in the form of a $4 \mathrm{~mm}$ thick plate was tested experimentally. $24 \mathrm{~h}$ tensile creep tests, preceded by standard tensile tests, were performed for various temperatures and different stress levels. Flat samples were cut out using a water jet machine (Fig. 1). Two types of specimens were developed based on ISO-527 standard [11]. Specimens in the shape of $1 \mathrm{~B}$ type were used in the static test at an ambient temperature (Fig. 1a). The length of the parallel measuring part of 1B type specimen was equal to $60 \mathrm{~mm}$ and the cross-section dimensions were equal to $10 \mathrm{x} 4 \mathrm{~mm}$. Specimens in the shape of 1BA type were used in the static test at elevated temperatures and in all creep tests (Fig. 1b). They had a shorter measuring part, due to chamber height limitation. The corresponding dimensions in the case of 1BA specimen were equal to $20 \mathrm{~mm}$ and $5 \times 4 \mathrm{~mm}$. 
a)

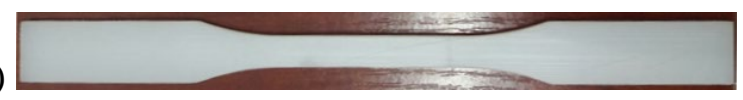

b)

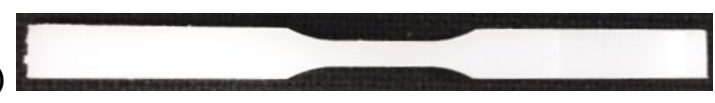

Fig. 1. ISO-527 specimens: a) 1B type for static standard test; b) 1BA type with a shorter measuring length for the tests in the temperature chamber

The structure of plastic exhibits a load memory effect [12]. Thus, the tested samples were preconditioned [13]. Before the tests, the samples were kept at the desired temperature for 4 hours or longer. Also, a furnace with the jaws inside, installed in the testing machine, was set to the desired temperature for at least $12 \mathrm{~h}$ to assure a uniform heat distribution in the entire work space of the chamber and in the jaws.

The PE plastic is characterized by a low moisture absorption equal to $<0.01 \%$ [3], [14]. Therefore, it was assumed that the humidity in the test bench room has an insignificant effect on the material properties.

a)

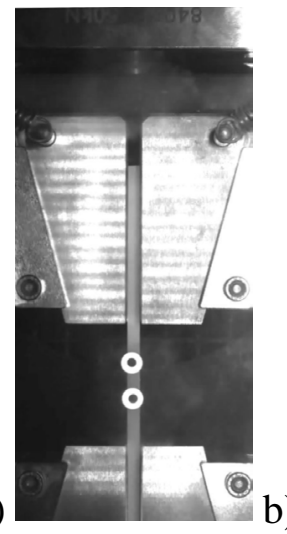

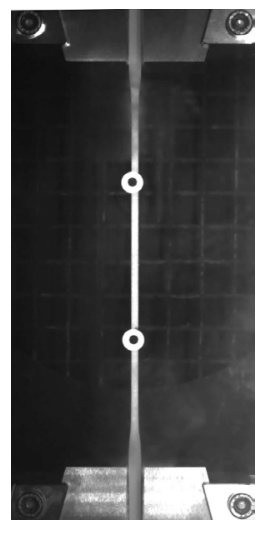

Fig. 2. An exemplary specimen installed in the temperature chamber: $a$ ) at the beginning and b) at the end of the test, with elongation limited by the furnace chamber dimensions

All the tests were performed on a creep testing machine equipped with an integrated videoextensometer. The videoextensometer allowed for elongation measurement of the specimen measuring length, excluding gripping parts, using digital image correlation methods (DIC). An exemplary specimen installed on the testing machine in the temperature chamber, with round black-and-white measuring marks for strain measurement, is presented in Fig. 2. Testing with a larger deformation is restrained in this study by instrumental limitations. Despite a shorter length of 1BA specimens, the internal dimensions of the temperature chamber limited the traverse displacement range and, thus, the maximum elongation of a sample during all tests at elevated temperatures (Fig. 2b) to $132 \mathrm{~mm}$.

A test program was established using three creep constitutive function variables: temperature, load and time. The maximum duration of the tests was set to 24 hours. The temperature values were determined based on the material PE1000 characteristics. Three temperature values were chosen: $22^{\circ} \mathrm{C}$ - corresponding to the normative test temperature [13]; $42^{\circ} \mathrm{C}$ - the tested material melting point, according to the Vicat method $\mathrm{A}$ [5], [15] and $90^{\circ} \mathrm{C}-$ marked as the maximum long-term working temperature for PE1000 polyethylene. Furthermore, the functional considerations of the material, in terms of a thermal point, (e.g. contact with human body or boiling water) were also taken into account. 


\section{Static test results}

To begin the creep experiment of the PE1000 material, it was necessary to perform static tensile tests. The material properties designated in the tensile tests provided a general view of the polyethylene UHMW behaviour. All static tests were carried out in accordance with the standard procedure [11] in the range of three fixed temperatures. Six specimens were tested for each temperature level. 1B type specimen shape was used at an ambient temperature (Fig. 1a), whereas 1BA type was used at elevated temperatures (Fig. 1b).

Static tests at $22^{\circ} \mathrm{C}$ resulted in the fracture of all samples. The measuring section of the samples deformed permanently along its entire length (Fig. 3). There was no clear necking of the measuring section. The material flowed evenly, constantly reducing the cross-sectional area of the section over time. The fracture formed edges almost perfectly perpendicular to the sample longitudinal axis. In Fig. 3, numerous buckling and torsions can be observed, which indicates a significant share of elastic energy in the sample prior the fracture.

The static tests at elevated temperatures lasted until the specified specimen elongation, limited by the size of the furnace chamber, occurred. The samples had a relatively uniform narrowing of the measuring section along its entire length.

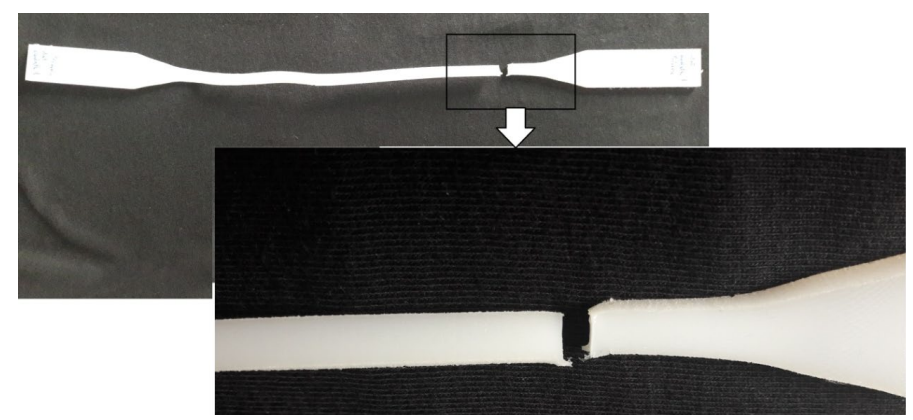

Fig. 3. Fracture of the exemplary specimen after the static test at an ambient temperature

Table 1. The results of PE1000 static tensile test at ambient and elevated temperatures

\begin{tabular}{|c|c|c|c|c|}
\hline \multirow{2}{*}{$\begin{array}{l}\text { Material property } \\
\text { description }\end{array}$} & \multirow{2}{*}{ Units } & \multicolumn{3}{|c|}{ Temperature $\left[{ }^{\circ} \mathrm{C}\right]$} \\
\hline & & 22 & 42 & 90 \\
\hline Young modulus E & \multirow{2}{*}[\mathrm{MPa}]{} & 1132.0 & 680.5 & 206.6 \\
\hline Standard deviation $\sigma_{\mathrm{E}}$ & & 10.7 & 59.3 & 19.4 \\
\hline Percentage decrease & [\%] & - & 39.9 & 81.7 \\
\hline $\begin{array}{c}\text { Ultimate strength } \mathrm{R}_{\mathrm{m}} / \\
\text { Stress at yield } \mathrm{R}_{\mathrm{e}} \\
\end{array}$ & \multirow{2}{*}[\mathrm{MPa}]{} & 21.3 & 15.3 & 7.6 \\
\hline $\begin{array}{c}\text { Standard deviation } \\
\sigma_{\mathrm{Rm}} \\
\end{array}$ & & 0.43 & 0.36 & 0.17 \\
\hline Percentage decrease & [\%] & - & 28.2 & 64.3 \\
\hline $\begin{array}{c}\text { Strain corresponding } \\
\text { to ultimate strength } \\
\varepsilon_{\mathrm{Rm}} \\
\end{array}$ & \multirow[t]{2}{*}{ [\%] } & 13.0 & 53.2 & 61.1 \\
\hline Standard deviation & & 2.20 & 2.40 & 7.30 \\
\hline
\end{tabular}

The results of polyethylene PE1000 static tensile tests at ambient and elevated temperatures are presented in Table 2. The elementary material properties such as Young modulus, ultimate strength and strain corresponding to ultimate strength were obtained for each given temperature 
level. Stress at yield point for typical plastic material curve according to [11], as in the case of the PE1000, has the same value as the ultimate strength. Standard deviation values were calculated. Also, a percentage decrease in the obtained material properties, relative to those achieved at ambient temperature, was determined.

$\sigma-\varepsilon$ tensile curves of PE1000 plastic for each temperature level based on the median values are presented in Fig. 4. It can be noticed that with an increase in the temperature of the material, the curve shape changes in the area of the yield point. The curve begins to take the form similar to a waveform with a conventional yielding point [11] and with postponed ultimate strength. The elastic range of the material response is significantly reduced. In the tests at $90^{\circ} \mathrm{C}$ and $42^{\circ} \mathrm{C}$, the samples fractures were not achieved due to the temperature chamber size limitations. Hence, their $\sigma-\varepsilon$ curves are shorter compared to the test at $22^{\circ} \mathrm{C}$.

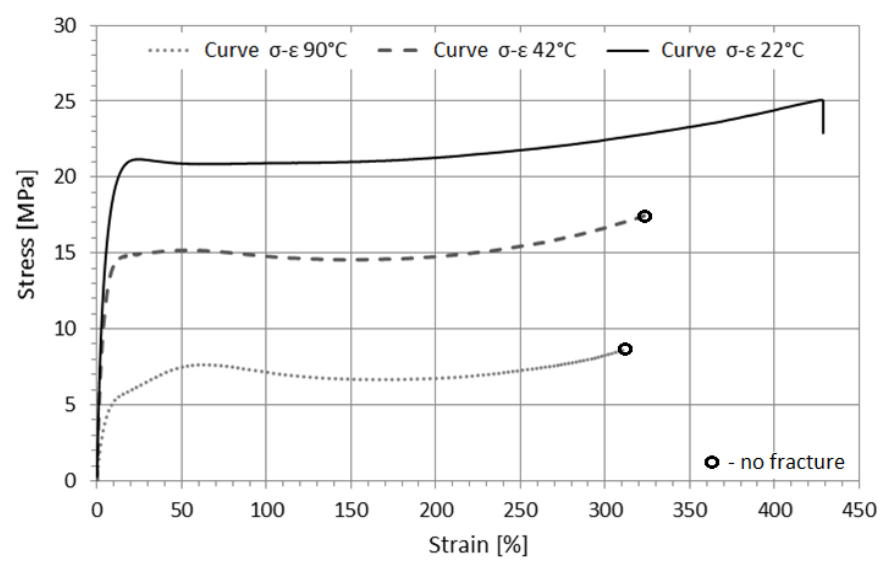

Fig. 4. Tensile curves of PE1000 plastic for each temperature level

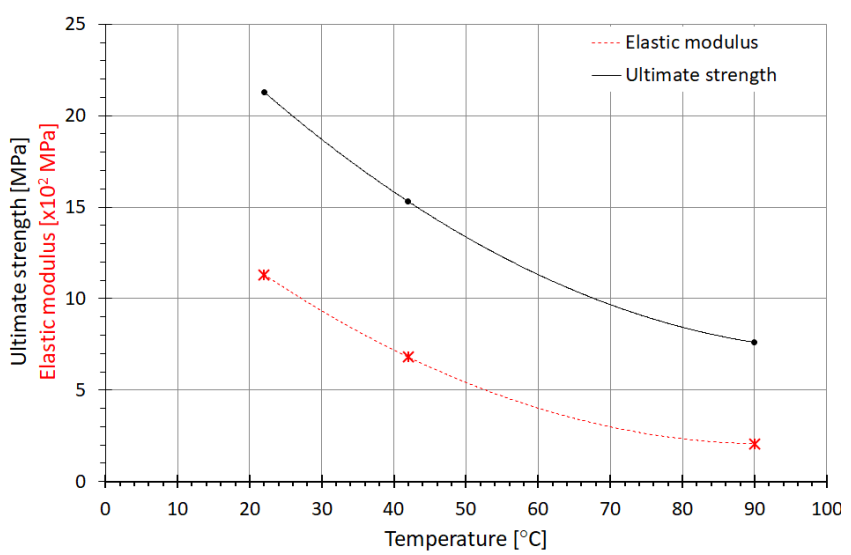

Fig. 5. Degradation of the PE1000 performance with temperature growth

Based on the presented results, it can be observed that the temperature rise degrades the material strength properties. With growth of the temperature, tensile curve histories (Fig. 4) as well as the material properties (Table 1) decrease. The dependencies of material properties on a temperature growth are nonlinear. In Fig. 5, tensile strength and elastic modulus data were approximated with polynomials of the second degree. The tensile strength value is reduced from 21.3 $\mathrm{MPa}$, at an ambient temperature, to $15.3 \mathrm{MPa}$ at $42^{\circ} \mathrm{C}$ and $7.6^{\circ} \mathrm{C}(64.3 \%$ decrease) at the highest temperature level. The elastic modulus declined from $1132 \mathrm{MPa}$ to 680.5 and even to 
203.6 MPa with respect to the temperature. The material stiffness is reduced by $81.7 \%$ at $90^{\circ} \mathrm{C}$, compared to properties at an ambient temperature (Table 1).

\section{Creep test results}

Creep tests were conducted at $22^{\circ} \mathrm{C}, 42^{\circ} \mathrm{C}$ and $90^{\circ} \mathrm{C}$ on the creep testing machine presented in Fig.2. 1BA modified sample type was used in the experiment. The tests were carried out on the basis of a procedure compliant with the PN-EN ISO 899-1 standard [16]. A creep test program had time limitations. However, to obtain statistical data in the selected cases three specimens were tested. The most representative data are shown in the paper. It was found that at the beginning and in the middle phase of creep, the specimens behaved repetitively. Some differences in creep curves occurred at the end of the tests.

The average material strength of the PE1000 at a given temperature (Table 1) was a reference point for stress values at creep. After calculation in respect to a cross section area it gives a reference stress of $21.3 \mathrm{MPa}($ load of $420 \mathrm{~N})$ at $22^{\circ} \mathrm{C}, 15.5 \mathrm{MPa}(310 \mathrm{~N})$ at $42^{\circ} \mathrm{C}$ and $7.5 \mathrm{MPa}$ $(150 \mathrm{~N})$ at $90^{\circ} \mathrm{C}$. The samples were loaded at given temperatures with seven multipliers of the reference stress: $0.9 ; 0.85 ; 0.8 ; 0.7 ; 0.6 ; 0.5$; and 0.4 . A stress level multiplier corresponds to a stress to ultimate tensile strength ratio. A detailed test program of creep loads is listed in Table 2.

Table 2. 24-h creep test programme of PE1000 plastic at ambient and elevated temperatures

\begin{tabular}{|c|c|c|c|c|c|c|}
\hline \multirow{2}{*}{$\begin{array}{c}\text { Stress level } \\
\text { multiplier (stress to } \\
\text { ultimate tensile } \\
\text { strength ratio) }\end{array}$} & \multicolumn{7}{|c|}{ Temperature } \\
\cline { 2 - 7 } & $\mathbf{2 2}{ }^{\circ} \mathbf{C}$ & $\mathbf{4 2}^{\circ} \mathbf{C}$ & $\mathbf{9 0}^{\circ} \mathbf{C}$ & $\mathbf{2 2}^{\circ} \mathbf{C}$ & $\mathbf{4 2}^{\circ} \mathbf{C}$ & $\mathbf{9 0}^{\circ} \mathbf{C}$ \\
\cline { 2 - 7 } $\begin{array}{c}\text { Reference value for } 1 x \\
\text { multiplier }\end{array}$ & 420 & 310 & 150 & 21.3 & 15.5 & 7.5 \\
\hline 0.9 & 383 & 279 & 135 & 19.1 & 14.0 & 6.8 \\
\hline 0.85 & 361 & 263 & 127 & 18.1 & 13.2 & 6.4 \\
\hline 0.8 & 340 & 248 & 120 & 17.0 & 12.4 & 6.0 \\
\hline 0.7 & 298 & 217 & 105 & 14.9 & 10.9 & 5.3 \\
\hline 0.6 & 255 & 186 & 90 & 12.8 & 9.3 & 4.5 \\
\hline 0.5 & 213 & 155 & 75 & 10.6 & 7.8 & 3.8 \\
\hline 0.4 & 170 & 124 & 60 & 8.5 & 6.2 & 3.0 \\
\hline
\end{tabular}

The tests lasted 24 hours at maximum which gives 86400 seconds. Time reduction to 24 hrs may be a reasonable option for practical applications and sufficient for numerical modelling purposes,[9], [10].

The test was usually finished after a $24 \mathrm{~h}$ period. Some load levels were so high at a given temperature that the creep test was completed in a much shorter time than set. At $22^{\circ} \mathrm{C}$, such cases resulted from the samples breaking. Four of the seven samples (for multipliers of 0.9, 0.85, 0.8 and 0.7 ) fractured, while three with the lowest multipliers lasted for 24 hours. The pictures of the samples after the creep test are presented in Fig. 6a). The specimens in Fig. 6 were placed next to each other, in order from the most loaded (on the left side) to the least loaded (on the right side).

At a higher temperature level, none of the samples was fractured and, in this case, reaching the safety traverse limit ended the tests earlier. This was the case for stress multipliers of 0.9 , 
0.85 and 0.8 . The other specimens lasted for 24 hours. The pictures of the samples after the creep at $42^{\circ} \mathrm{C}$ are presented in Fig. 6b). The corresponding $24 \mathrm{~h}$-creep curves are presented in Fig. 8.

In the case of the tests at the $90^{\circ} \mathrm{C}$, safety limits were not also obtained. The pictures of the samples are presented in Fig. 6c). 24h-creep curves at $90^{\circ} \mathrm{C}$ are presented in Fig. 9.
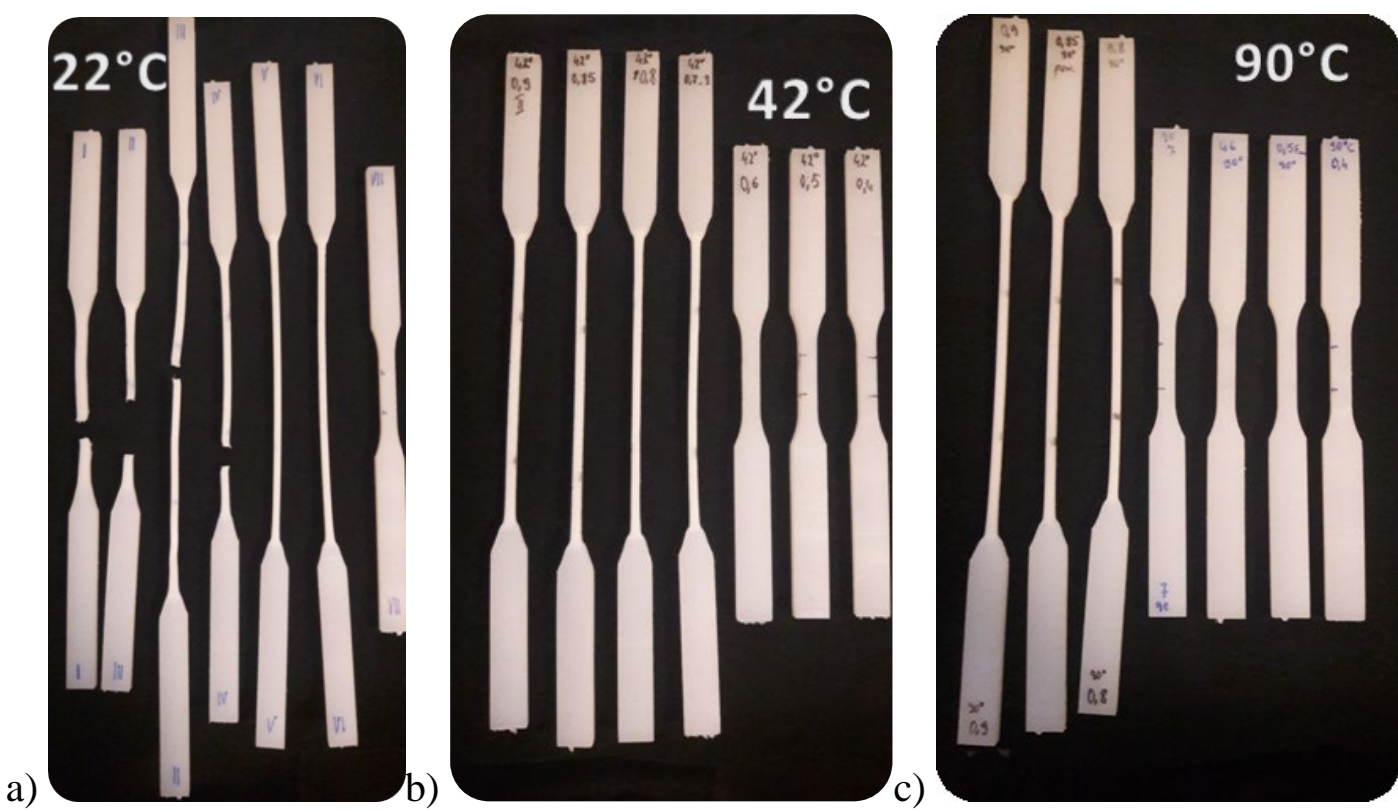

Fig. 6. Specimens after the $24 \mathrm{~h}$ creep tests at ambient temperature (a) at $42^{\circ} \mathrm{C}$ (b) and at $90^{\circ} \mathrm{C}$ (c). Stress level decreases from the left to the right side of the pictures

As presented in Fig. 6a-c), fractures of the broken specimens were similar to those formed in the static tests. The samples which were not broken had a relatively uniformly narrowed measuring section along its whole length.

The final elongation depends on the stress level. The lower the stress the less the total elongation. This is the case for specimens stressed at $42^{\circ} \mathrm{C}$ and $90^{\circ} \mathrm{C}$. At those temperatures none of the specimens fractured. The specimens stressed with a low multiplier (to 0.6 at $42^{\circ} \mathrm{C}$ and 0.7 at $90^{\circ} \mathrm{C}$ ) obtained significantly lower total elongation than the specimens with higher multiplier, in which participation of ductile strain is high. Minor elongation differences can be caused by differences in fixturing of a given specimen.

At an ambient temperature, the resulted elongations of broken specimens are inconsistent. One of the specimens ( third from the left in Fig. 6a) stressed to a lower level was subjected to a more ductile deformation in the total elongation than other fractured specimens. Moreover, in the case of the specimens loaded with the highest stress multipliers ( 0.9 and 0.85 ), the ductile strain share was lower compared to others, except for the 0.4. multiplier.

24h-creep curves of PE1000 plastic at $22^{\circ} \mathrm{C}$ are presented in Fig. 7. At ambient temperature, the material passes, during creep, into a state of plastic flow under loads equivalent to, or more than, $0.5 \mathrm{R}_{\left(22^{\circ} \mathrm{C}\right)}$, which is about $\sigma=10 \mathrm{MPa}$. At $42^{\circ} \mathrm{C}$ (Fig. 8), the second creep stage occurs under stress equal to at least $0.7 \mathrm{R}_{\left(42^{\circ} \mathrm{C}\right)}(\sigma=10.0 \mathrm{MPa})$. At $90^{\circ} \mathrm{C}$ (Fig. 9), this is the case under stress of $\sigma=6.0 \mathrm{MPa}$ and more $\left(\geq 0.8 \mathrm{R}_{\mathrm{m}\left(90^{\circ} \mathrm{C}\right)}\right)$. The higher the temperature of the material, the lower stress is able to induce the flow process, however, with respect to the strength at a given temperature, a creep stress to an ultimate strength ratio increases. 


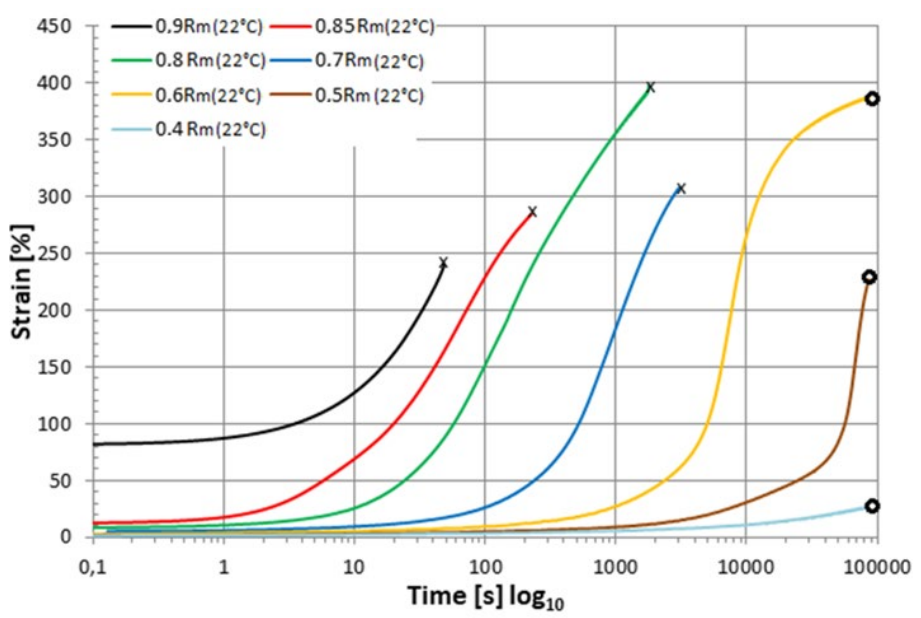

Fig. 7. 24h creep curves of PE1000 plastic at $22^{\circ} \mathrm{C}$

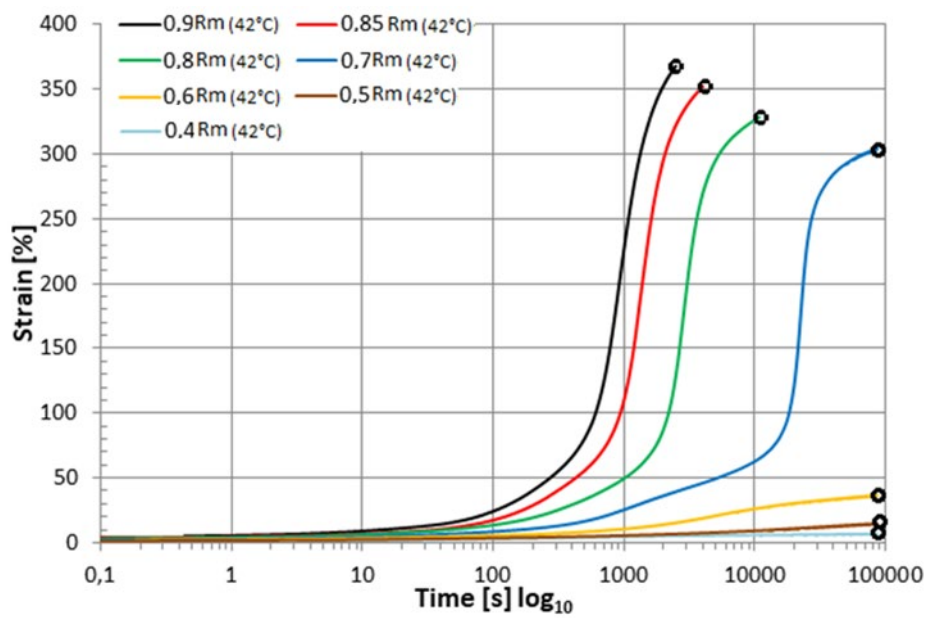

Fig. 8. 24 h creep curves of PE1000 plastic at $42^{\circ} \mathrm{C}$

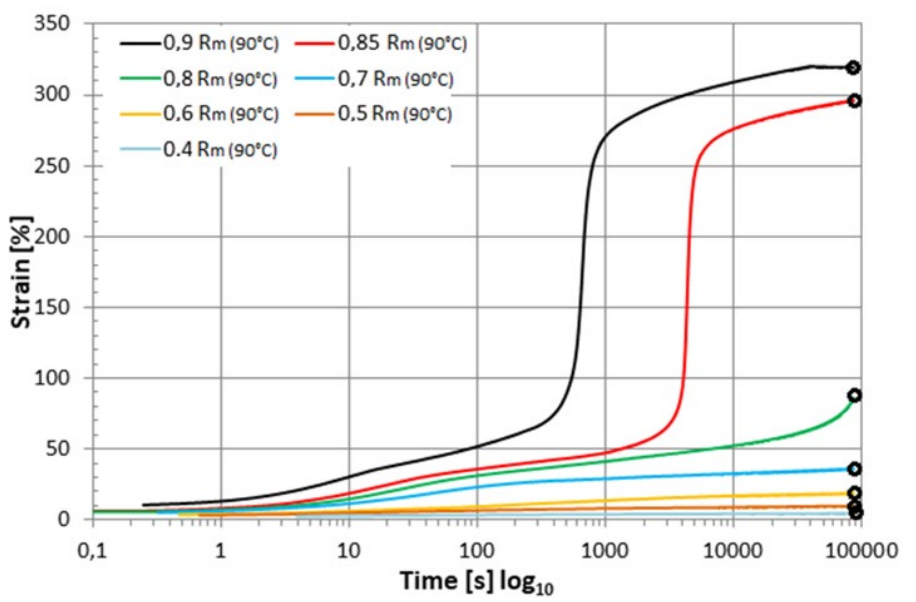

Fig. 9. 24h creep curves of PE1000 plastic at $90^{\circ} \mathrm{C}$

At $22^{\circ} \mathrm{C}$ an unexpected phenomenon occurred in the case of creep curves at stress level multipliers of 0.5 and 0.6 . After about $1000 \mathrm{~s}$ or more, the curves rapidly increased as if it would be III creep stage and, after reaching a specific higher strain, a strain ratio decreased (Fig. 7). For higher multipliers, the specimens crushed. This phenomenon is explained by hardening of the material under high deformations, which caused a strain ratio to decrease. A similar phenomenon 
is present in the case of the elevated temperatures, at $42^{\circ} \mathrm{C}$, in the case of multipliers of 0.7 and higher and at $90^{\circ} \mathrm{C}$, in the test of a 0.85 and a 0.9 stress multiplier. In [10] a similar behaviour is present in some cases of $24 \mathrm{~h}$-creep graphs for polyethylene, however, it is not explained.

Table 3. Time required to achieve specific deformation of $30 \%$ and $150 \%$ or crush

\begin{tabular}{|c|c|c|c|c|c|c|c|}
\hline Temperature & \multicolumn{3}{|c|}{$22^{\circ} \mathrm{C}$} & \multicolumn{2}{|c|}{$42^{\circ} \mathrm{C}$} & \multicolumn{2}{|c|}{90} \\
\hline $\begin{array}{l}\text { Reference } \\
\text { stress value }\end{array}$ & \multicolumn{3}{|c|}{21.3} & \multicolumn{2}{|c|}{15.5} & \multicolumn{2}{|c|}{7.5} \\
\hline Strain level & $30 \%$ & $150 \%$ & crush & $30 \%$ & $150 \%$ & $30 \%$ & $150 \%$ \\
\hline $\begin{array}{c}\text { Stress level } \\
\text { multiplier }\end{array}$ & \multicolumn{7}{|c|}{ Time [s] } \\
\hline 0.9 & - & 16 & 48 & 136 & 781 & 10 & 636 \\
\hline 0.85 & 2.8 & 41 & 226 & 211 & 1187 & 37 & 4673 \\
\hline 0.8 & 13 & 98 & 1786 & 415 & 2655 & 80 & - \\
\hline 0.7 & 120 & 778 & 3035 & 1331 & 21389 & 1738 & - \\
\hline 0.6 & 1149 & 6436 & - & 18233 & - & - & - \\
\hline 0.5 & 9582 & 67156 & - & - & - & - & - \\
\hline 0.4 & - & - & - & - & - & - & - \\
\hline
\end{tabular}

The temperature increase degrades the strength and creep parameters of the material. During creep, both at an ambient temperature and at the elevated temperatures, the dependence of the time required to achieve a specific plastic deformation or crush, as a function of the nominal stress, decreases exponentially. In Table 3, times required to achieve a specific deformation or crush are listed. Only specimens evaluated in $22^{\circ} \mathrm{C}$ were broken. For 0.9 , crush occurred after $48 \mathrm{~s}$ while in the case of 0.8 -after $1789 \mathrm{~s}$ and 0.7 - after $30355 \mathrm{~s}$. Strains of $30 \%$ and $150 \%$ were arbitrary selected as an example. $150 \%$ of strain at $42^{\circ} \mathrm{C}$ is obtained after $781 \mathrm{~s}$ for 0.9 multiplier and after $21389 \mathrm{~s}$ for 0.7 multiplier. Similarly, at $90^{\circ} \mathrm{C}, 150 \%$ is reached after $636 \mathrm{~s}$ at 0.9 load level and 4673 at a 0.85 load level (Table 3).

\section{Conclusions}

The final conclusions on the basis of the static tensile and 24h-creep tests under the tensile load of polyethylene PE1000, at ambient and elevated temperatures up to $90^{\circ} \mathrm{C}$, were formulated:

- The temperature increase degrades nonlinearly performance of the material. The strength properties such as ultimate tensile strength and Young's modulus are reduced;

- At an ambient temperature, the material passes, during creep, into a state of plastic flow under stress values: $\geq 0.5 \mathrm{R}_{\left(22^{\circ} \mathrm{C}\right)}, \geq 0.7 \mathrm{R}_{m\left(42^{\circ} \mathrm{C}\right)}$ and $\geq 0.8 \mathrm{R}_{\mathrm{m}\left(90^{\circ} \mathrm{C}\right)}$ at corresponding temperature. The higher the temperature of the material, the lower stress is able to induce the flow process, however, with respect to the strength at a given temperature, a creep stress to an ultimate strength ratio increases;

- The dependence of the time required to achieve a specific plastic deformation or crush, as a function of the stress level at given temperature, decreases exponentially;

- Under high load level multipliers, at deep II creep stage, the curves rapidly increase as if it would be III creep stage and, after reaching a specific higher strain value, a strain ratio decreased. This phenomenon is explained by hardening of the material under high deformations, which caused a strain ratio to decrease. 


\section{References}

[1] S. Ochelski, Experimental methods in construction composites mechanics [in Polish], WNT Wydawnictwa Naukowo-Techniczne, Warsaw 2004

[2] M. Kutz, Applied plastics engineering handbook. Processing and materials, Elsevier, Waltham (2011)

[3] Information on: https://www.redwoodplastics.com/wp-content/uploads/2016/02/RedcoUHMW-Performance-Plastics-Feb2016.pdf

[4] Information on:

https:/www.mtf.stuba.sk/buxus/docs/internetovy_casopis/2010/3/szeteiova.pdf

[5] Information on http://www.plastics.pl/content/pliki/213/katalog_tworzywa_tech17.pdf (2018)

[6] D.V. Rosato, M.G. Rosato, D.V. Rosato, Concise encyclopedia of plastics, SpringerScience+Business Media, LLC, Kluwer Academic Publishers, Boston (2000). https://doi.org/10.1007/978-1-4615-4579-8

[7] M. Ashby, H. Shercliff, D. Cebon, Material engineering vol.1 [in Polish], Galaktyka, Łódź (2010)

[8] A. Jakowluk, Creep and fatigue processes in materials [in Polish], WNT, Warsaw (1993)

[9] L. Hongtao, M.A. Polak, A. Penlidis, A Practical Approach to Modeling Time-Dependent Nonlinear Creep Behavior of Polyethylene for Structural Applications, Polymenr engineering and science (2008), pp.159-167. https://doi.org/10.1002/pen.20942

[10] L. Hongtao, Material Modelling for Structural Analysis of Polyethylene A thesis of Master of Applied Science, University of Waterloo, Waterloo, Ontario, Canada (2007)

[11] PN-EN ISO 527-2:2012 Plastics -- Determination of tensile properties -- Part 2: Test conditions for moulding and extrusion plastics [in Polish], Polski Komitet Normalizacyjny PKN, Warsaw (2012). https://doi.org/10.3403/30216860

[12] I. Hyla, Plastics - properties - processing - application[in Polish], Wydawnictwo Politechniki Śląskiej, Gliwice (2004)

[13] PN-EN ISO 291:2010 Plastics -- Standard atmospheres for conditioning and testing [in Polish], Polski Komitet Normalizacyjny PKN, Warsaw (2010)

[14] Information on https://crownplastics.com (2018)

[15] S.M. Kurtz, The UHMWPE Handbook: Ultra-High Molecular Weight Polyethylene in Total Joint Replacement, Elsevier, Philadelphia (2004)

[16] PN-EN ISO 899-1:2005 Plastics — Determination of creep behaviour —Part 1:Tensile creep [in Polish], Polski Komitet Normalizacyjny PKN, Warsaw (2005) 